\title{
SUSCEPTIBILIDADE ANTIMICROBIANA DE AMOSTRAS DE ESCHERICHIA COLI ISOLADAS DE FRANGO INDUSTRIAL (GALLUS GALLUS DOMESTICUS - LINNAEUS, 1758) COM COLIBACILOSE
}

\section{G.A. Marietto Gonçalves; R.L. Andreatti Filho}

Universidade Estadual Paulista, Faculdade de Medicina Veterinária e Zootecnia, Departamento de Clínica Veterinária, Laboratório de Ornitopatologia, CP 560, CEP 18618-000, Botucatu, SP, Brasil. E-mail: gmarietto_ornito@fmvz.unesp.br

\section{RESUMO}

\begin{abstract}
O presente estudo avaliou a susceptibilidade de amostras de Escherichia coli isoladas de quadros de colissepticemia aviária da região centro-oeste paulista pelo Laboratório de Ornitopatologia da FMVZ-UNESP/Botucatu, SP. Constatou-se um grande número de amostras multirresistentes aos antibióticos testados, onde as drogas menos efetivas foram sulfonamida e tetraciclina. Todas as amostras mostraram-se sensíveis a norfloxacina e gentamicina.
\end{abstract}

PALAVRAS-CHAVE: Escherichia coli, antibiograma, ornitopatologia, saúde animal.

\begin{abstract}
ANTIMICROBIAL SUSCEPTIBILITY OF SAMPLES OF ESCHERICHIA COLI ISOLATED FROM INDUSTRIAL CHICKENS (GALLUS GALLUS DOMESTICUS - LINNAEUS, 1758) WITH COLIBACILLOSIS. The present study evaluated the susceptibility of Escherichia coli samples isolated from poultry with colisepticemia in midwestern São Paulo State at the Ornitopathology Laboratory of FMVZ-UNESP/Botucatu, SP. A large number of samples were found that were multi-resistant to the antibiotics tested, the less effective drugs being sulfonamide and tetracycline. All samples were susceptible to norfloxacin and gentamicin.
\end{abstract}

KEY WORDS: Escherichia coli, antibiogram, avian pathology, animal health.

Escherichia coli é uma bactéria anaeróbia facultativa pertencente à microbiota normal do trato intestinal de animais e seres humanos (BONTEN et al., 1990). A infecção por E. coli (colibacilose) é uma das principais doenças da avicultura industrial moderna, devido aos grandes prejuízos econômicos causados no mundo inteiro (FerReIRA; KNOBL, 2000). $\mathrm{O}$ uso indiscriminado de antimicrobianos, as subdosagens e a adição de promotores de crescimento à dieta, que expõe os animais por longos períodos a pequenas concentrações de antibióticos, colaboraram para a seleção e manutenção de organismos resistentes (McEwEN; FEDORKA-CRAY, 2002; ANDREATTI FILHO, 2007).

A resistência microbiana pode ser associada a um aumento na virulência da cepa, resultante da aquisição de genes com fatores de resistência e também pela escolha empírica do agente de tratamento, antes do teste de susceptibilidade (TRAVERS; BARZA, 2002).

Um antibiograma é um ensaio que mede a susceptibilidade/resistência de uma bactéria a um ou mais agentes antimicrobianos (KonEMAN et al., 1992).
Pode ser utilizado tanto para análise do espectro de sensibilidade/resistência a drogas de uma bactéria, quanto para determinação da concentração mínima inibitória.

O presente trabalho avaliou a susceptibilidade de cepas de E. coli isoladas de aves industriais com quadro de colibacilose atendidas no Laboratório de Ornitopatologia do Hospital Veterinário da Faculdade de Medicina Veterinária e Zootecnia da Universidade Estadual Paulista, campus de Botucatu, SP, perante alguns antibióticos utilizados na prática veterinária.

Foram necropsiadas aves de diversas idades e finalidades (pintinhos, frango de corte e reprodutoras) com suspeita clínica de colibacilose, tendo-se coletado de forma asséptica com o auxílio de tesouras e pinças estéreis, órgãos (saco vitelino, sacos aéreos, pulmão, coração, ovário e oviduto) com lesões macroscópicas sugestivas da doença. Após a coleta, os órgãos foram acondicionados em frascos estéreis e imediatamente processados.

Após maceração, os fragmentos de órgãos foram inoculados em caldo cérebro-coração (Oxoid) e in- 
cubados a $37^{\circ} \mathrm{C}$ por 24 horas. Após esse período, semeou-se o caldo em ágar MacConkey (Merck) e verde brilhante (Intermédia), sendo novamente incubados a $37^{\circ} \mathrm{C}$ por 24 horas, conforme descrição de ARP (1989). Após a verificação de amostras sugestivas para E. coli, confirmou-se o diagnóstico por meio de série bioquímica, de acordo com Holt et al. (1994). Após a identificação, as amostras foram armazenadas em tubos com ágar nutriente (Difco).

Para a realização dos antibiogramas utilizouse o método proposto por BAUER et al. (1966). Primeiramente as amostras foram cultivadas em caldo Miller-Hilton (Difco), incubadas a $37^{\circ} \mathrm{C}$ por 24 horas. Pipetou-se 0,1 mL de cada caldo (de cada amostra) em placas de ágar Mueller-Hilton (Difco), espalhando-se de forma homogênea a gota por toda a superfície da placa com o uso de alça de Drigalski. Em seguida, depositaram-se os discos contendo os antibióticos utilizados no estudo. Por fim as placas foram incubadas a $37^{\circ}$ C por 24 horas, realizando-se a leitura após este período.

Foram testadas 17 drogas antibióticas: ácido nalidíxico (NAL 30mcg), amoxicilina (AMO 10 $\mathrm{mcg}$ ), ampicilina (AMP $10 \mathrm{mcg}$ ), cefaclor (CFC 30 $\mathrm{mcg}$ ), ceftiofur (CTF $30 \mathrm{mcg}$ ), ciprofloxacina (CIP $5 \mathrm{mcg}$ ), cloranfenicol (CLO $30 \mathrm{mcg}$ ), enrofloxacina (ENO $5 \mathrm{mcg}$ ), estreptomicina (EST $10 \mathrm{mcg}$ ), gentamicina (GEN $10 \mathrm{mcg}$ ), neomicina (NEO $30 \mathrm{mcg}$ ), norfloxacina (NOR $10 \mathrm{mcg}$ ), perfloxacina (PEF 5 mcg), sulfonamida (SUF $300 \mathrm{mcg}$ ), tetraciclina (TET $30 \mathrm{mcg}$ ), trimetoprim (TRI $5 \mathrm{mcg}$ ). Todos os discos de antibióticos testados eram da marca Sensifer ${ }^{\circledR}$ (Cefar).

Foram isoladas 27 amostras de E. coli oriundas de quadros de colibacilose. Os resultados dos anti- biogramas estão contidos na Tabela 1. Das amostras isoladas, somente uma amostra mostrou-se sensível a todos os antibióticos testados. Observou-se que sete amostras apresentaram resistência somente a uma droga, 14 apresentaram resistência a duas ou três drogas e cinco apresentaram multi-resistência entre seis e oito drogas.

Das amostras multirresistentes notou-se que 12 apresentaram interação de resistência entre SUF/ TET, seis SUL/NEO e cinco SUL/NAL, sendo que entre estas também coincidiram a associação multirresistente de SUL/TET/NEO em quatro amostras, SUL/TET/TRI e SUL/TET/NEO/NAL em três amostras cada uma.

Nesse estudo foram utilizados oito grupos de antibióticos: aminoglicosídeos (EST, GEN, NEO), cefalosporinas (CFC, CTF), cloranfenicol (CLO), diaminopirimidinas (TRI), quinolonas (ENO, CIP, NAL, NOR e PER), penicilinas (AMO, AMP), sulfas (SUL) e tetraciclinas (TET). Destes, a sulfa foi o grupo farmacológico que apresentou um menor grau de inibição com 59,2\% das amostras bacterianas resistentes, seguida por tetraciclina $(44,4 \%)$ pelas quinolonas e aminoglicosídeos (ambos com 40,7\%), penicilinas $(14,8 \%)$, diaminopirimidina $(11,1 \%)$, cefalosporinas $(7,4 \%)$ e o cloranfenicol sendo o grupo com melhor desempenho com apenas 3,7\% de amostras resistentes.

Notou-se resistência em quase todas as drogas testadas, onde somente a ciprofloxacina, norfloxacina e gentamicina não apresentaram amostras resistentes, sendo as duas últimas (norfloxacina e gentamicina) totalmente eficientes, ao contrário do observado por BlANCO et al. (1997), CARDOSO et al. (2002), VAN Den BogaArd et al. (2001) e ZanatTa et al. (2004) que relataram um alto índice de resistência a estes antibióticos.

Tabela 1 - Susceptibilidade apresentada pelas 27 amostras de Escherichia coli frente aos antibióticos testados.

\begin{tabular}{lccc}
\hline Antibióticos & Sensível No $(\%)$ & Intermediário $\mathrm{N}^{\circ}(\%)$ & Resistência No $(\%)$ \\
\hline Ácido Nalidíxico & $17(63)$ & 0 & $10(37)$ \\
Amoxicilina & $4(14,8)$ & $20(74)$ & $3(11,2)$ \\
Ampicilina & $26(96,3)$ & 0 & $1(3,7)$ \\
Cefaclor & $2(7,4)$ & $23(82,2)$ & $2(7,4)$ \\
Ceftiofur & $13(48)$ & $13(48)$ & $1(4)$ \\
Ciprofloxacina & $26(96,3)$ & $1(3,7)$ & 0 \\
Cloranfenicol & $26(96,3)$ & 0 & $1(3,7)$ \\
Enrofloxacina & $21(77,8)$ & $4(14,8)$ & $2(7,4)$ \\
Estreptomicina & $20(74)$ & $4(14,8)$ & $3(11,2)$ \\
Gentamicina & $27(100)$ & 0 & 0 \\
Neomicina & $14(51,9)$ & $2(7,4)$ & $11(40,7)$ \\
Norfloxacina & $27(100)$ & 0 & 0 \\
Perfloxacina & $19(70,4)$ & $2(7,4)$ & $6(22,2)$ \\
Sulfanamida & $8(29,6)$ & $1(3,7)$ & $18(66,7)$ \\
Tetraciclina & $14(52)$ & 0 & $13(48)$ \\
Trimetoprim & $24(88,8)$ & 0 & $3(11,2)$ \\
\hline
\end{tabular}


Além de norfloxacina e gentamicina, outras drogas apresentaram uma boa eficiência, porém com algumas poucas amostras resistentes igualmente a Shareef (2004), Malik et al. (2005) e Miles et al. (2006) foram ampicilina, trimetoprim ecloranfenicol, enquanto AL-GHAmDi et al. (1999) e ZanATTA et al. (2004) observaram um alto índice de resistência para ampicilina, BlANCO et al. (1997) para trimetoprim.

Como observado por BlANCO et al. (1997) e MALIK et al. (2005), a perfloxacina, enrofloxacina e estreptomicina apresentaram um bom índice de sensibilidade, apesar de se observarem amostras resistentes, contrariandoSCHROEDER et al. (2002) e MiLES et al. (2006) que observaram alta resistência para estreptomicina e enrofloxacina, respectivamente.

Ceftiofur e o cefaclor foram drogas que apresentaram um baixo índice de resistência, porém se apresentaram com um espectro de ação intermediário, diferente de Schroeder et al. (2002) e MALIK et al. (2005) que observaram uma boa eficiência com o ceftiofur e com outras cefalosporinas, com exceção da cefalotina que nestes estudos apresentou resistência.

Outra droga que apresentou um espectro de ação intermediário com uma quantidade baixa de amostras resistente foi a amoxicilina, assim como observado por BlANCO et al. (1997), SCHROEDER et al. (2002) e Miles et. al. (2006). O ácido nalidíxico apresentou uma boa quantidade de amostras sensíveis, mas com uma quantidade relativamente alta de amostras resistentes, semelhante ao observado por BLANCO et al. (1997) e Miles et al. (2006).

Tetraciclina e neomicina apresentaram-se como drogas de efetividade mediana, pois, nas amostras estudadas, os números de amostras resistentes quase que se equivaleram com as amostras sensíveis, semelhante à MALIK et al. (2005) para tetraciclina e BLANCO et al. (1997) para neomicina, mas estes últimos autores, como SCHROEDER et al. (2002) e Miles et al. (2006), observaram um alto índice de resistência à tetraciclina e VAN Den BogaARD etal. (2001) à neomicina. Das drogas testadas, a sulfonamida foi a que apresentou o maior índice de resistência bacteriana, semelhante ao observado por todos os autores consultados neste estudo.

$\mathrm{O}$ alto índice de resistência à sulfonamida pode ser atribuído principalmente pelo seu emprego em larga escala no controle e erradicação de outros agentes patogênicos, neste caso, principalmente contra coccídeos. Drogas como a tetraciclina, ácido nalidíxico e neomicina são muito utilizadas por serem de baixo custo e fácil obtenção, o que explica também o número de amostras com resistência. As penicilinas, cefalosporinas, trimetoprim, estreptomicina, enrofloxacina e perfloxacina foram drogas de perfil inibitório razoável neste estudo. Devido ao excelente desempenho, a ciprofloxacina, norfloxacina e gentamicina podem ser possíveis drogas de primeira escolha em um surto de colibacilose "a campo".
Apesar do observado nesse estudo, a prática da análise de perfil de sensibilidade sempre deve ser avaliada conforme uma nova amostra é isolada, pois esta pode variar conforme a região geográfica, as drogas disponíveis no mercado e o seu poder econômico.

Com os resultados deste estudo concluiu-se que sulfanamida e tetraciclina são as drogas que apresentaram menor eficácia para o tratamento de colibacilose devido ao alto índice de resistência, e ciprofloxacina, norfloxacina e gentamicina são drogas totalmente eficientes com ausência total de resistência na avaliação in vitro, o que as tornam possíveis drogas de primeira escolha em casos de surto de colibacilose aviária na região de Botucatu, SP.

\section{REFERÊNCIAS}

AL-GHAMDI, M.S.; EL-MORSY, F.; AL-MUSTAFA, Z.H.; AL-RAMADHAM,M.; HANIF, M. Antibiotic resistence of Escherichia coli isolated from poultry workers, patients and chicken in the eastern province of Saudit Arabia. Tropical Medicine and International Health, v.4, n.4, p.278-283, 1999.

ANDREATTI FILHO, R.L. Colibacilose Aviária. In: ANDREATTI FILHO, R.L. (Ed.). Saúde aviária e doenças. São Paulo: Roca, 2007. p.112-117.

ARP, L.H. Collibacillosis. In. CHAIRMAN, H.G.P.; ARP, L.H.; DOMERMUTH, C.H.; PEARSON, J.E. (Ed.). A laboratory manual for the isolation and identificatiom of avian pathogens. 3.ed. Jacksonville: The American Assotiation of Avian Pathologists, 1989. p.12-13.

BAUER, A.W.; KIRBY, W.M.; SHERRIS, J.C.; TURK, M. Antibiotic susceptibility testing by a standardized single disc method. American Journal of Clinical Pathology, v.45, p.493-496, 1966.

BLANCO, J.E.; BLANCO, M.; MORA, A.; BLANCO, $\mathrm{J}$. Prevalence of bacterial resistence to quinolones and other antimicrobials among avian Escherichia coli strains isolated from septcemic and helthy chickens in Spain. Journal of Clinical Microbiology, v.35, n.8, p.2184-2185, 1997.

BONTEN, M.; STOBBERINGH, E.; HOUBEN, A. High prevalence of antibiotic resistant Escherichia coli in faecal samples of students in the south-east of the Netherland. Journal of Antimicrobial Chemotherapy, v.26, p.585-592, 1990.

CARDOSO, A.L.S.P.; TESSARI, E.N.C.; CASTRO, A.G.M.; ZANATTA, G.F. Avaliação da susceptibilidade a antimicrobianos de cepas de Escherichia coli de origem aviária. Arquivos do Instituto Biológico, São Paulo, v.69, n.2, p.1-5, 2002. 
FERREIRA, A.J.P.; KNÖBL, T. Colibacilose aviária. In. BERCHIERI JÚNIOR, A.; MACARI, M. (Ed.). Doenças das aves. Campinas: FACTA, 2000. p.198-207.

HOLT, J.G.; KRIEG, N.R.; SNEATH, P.H.A.; STALEY, J.T.; WILLIAMS, S.T. Bergey's manual of determinative bacteriology. 9.ed. Baltimore: Willians \& Wilkins, 1994. p.787.

KONEMAN, E.W.; ALLEN, S.T.; JANDA, W.M.; SCHRECKENBERGER, P.C.; WINN JUNIOR, W.C. Color atlas and textbook of diagnostic microbiology. 4.ed. Philadephia: J. B. Lippincott, 1992. 1154p.

MALIK, Y.S.; CHANDER, Y.; GUPTA, S.C.; GOYAL, S.M. A retrospective study on antimicrobial resistence in Mannheimia (Pasteurella) haemolytica, Escherichia coli, Salmonella species, and Bordetella avium from chickens in Minnesota. Journal of Applied Poultry Research, v.14, p.506-511, 2005.

McEWEN, S.A.; FEDORKA-CRAY, P.J. Antimicrobial use and resistance in animals. Clinical Infectious Diseases, v.34, n.3, p.93-106, 2002.

MILES, T.D.; McLAUGHLIN, W.; BROWN, P.D.

Antimicrobial resistence of Escherichia coli isolates from broiler chickens and humans. Veterinary research, v.2, n.7, 2006. Disponível em: <http:/ / www.biomedcentral. com/1746-6148/2/7>.
SCHROEDER, C.M.; MENG, J.; ZHAO, S.; DEBROY, C.; TORCOLINI, J.; ZHAO, C.; McDERMOTT, P.F.; WAGNER, D.D.; WALKER, R.D.; WHITE, D.G. Antimicrobial resistence of Escherichia coli O26, O103, O111, 128, and 145 from animals an humans. Emerging Infections Diseases, v.8, n.12, p.1409-1414, 2002.

SHAREEF, A.M. Prevalence of antimicrobial resistance in Escherichia coli isolated from broiler chickens with air sacculitis in Ninevah governorate, 1999-2002. Iraqi Journal of Veterinary Sciences, v.18, n.1, p.15-26, 2004.

TRAVERS, K.; BARZA, M. Morbidity of infections caused by antimicrobial-resistant bacteria. Clinical Infectious Diseases, v.34, n.3, p.131-134, 2002.

VAN DEN BOGAARD, A.E.; LONDON, N.; DRIESSEM, C.; STOBBERINGH, E.E. Antibiotic resistance of faecal Escherichia coli in poultry, poultry farmers and poultry slaughthterers. Journal of Antimicrobial Chemotherapy, v.47, p.763-771, 2001.

ZANATTA, G.F.; KANASHIRO, A.M.I.; CASTRO, A.G.M.; CARDOSO, A.L.S.P.; TESSARI, E.N.C.; PULICI, S.C.P. Susceptibilidade de amostras de Escherichia coli de origem aviária a antimicrobianos. Arquivos do Instituto Biológico, São Paulo, v.71, n.3, p.283-286, 2004.

Recebido em 1/3/09

Aceito em 28/10/10 